\title{
Simulação computacional como ferramenta de otimização na geração de energia solar fotovoltaica
}

\author{
Computational simulation as an optimization tool for photovoltaic solar energy \\ generation
}

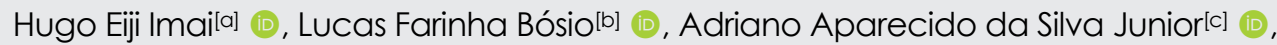

Lilian Keylla Berto[a] (ㄱ, Natália Ueda Yamaguchi[d,e] (ㄱ), Luciana Cristina Soto Herek Rezende[d,e] (1)

\author{
[a] Universidade UniCesumar, Maringá, PR, Brasil \\ [b] Universidade Estadual de Maringá (UEM), Maringá, Brasil \\ [c] Universidade Tecnológica Federal do Paraná (UTFPR), Campo Mourão, PR, Brasil \\ [d] Instituto Cesumar de Ciência, Tecnologia e Inovação - ICETI, Maringá, PR, Brasil \\ [e] Universidade UniCesumar, Programa de Pós-graduação em Tecnologias Limpas, Maringá, PR, Brasil
}

Como citar: Imai, H. E., Bósio, L. F., Silva Junior, A. A., Berto, L. K., Yamaguchi, N. U., \& Rezende, L. C. S. H. (2020). Simulação computacional como ferramenta de otimização na geração de energia solar fotovoltaica. urbe. Revista Brasileira de Gestão Urbana, 12, e20190343. https://doi.org/10.1590/2175-3369.012.e20190343

\section{Resumo}

Nos últimos anos, o crescimento econômico e populacional causou um aumento na demanda de energia, o que, por consequência, impulsionou o desenvolvimento e as melhorias de sistemas de energia renovável, e em especial no Brasil, da energia proveniente de painéis fotovoltaicos. Diante deste cenário, este artigo objetivou otimizar o sistema de geração de energia solar fotovoltaica de uma empresa com a finalidade de contribuir com a matriz energética e o desenvolvimento sustentável urbano pela aplicação da modelagem matemática e simulação com o uso do software MATLAB ${ }^{\circledR}$ (versão 2018), por meio da análise de dados meteorológicos e das especificações do sistema de módulos, por um período de 12 meses. No total, foram apresentadas três simulações que otimizaram o sistema instalado. No entanto, foi possível ressaltar o melhor modelo proposto, que resultou em $75.220 \mathrm{kWh} /$ ano de geração de energia e proporcionou um ganho de geração de 2,35\%, correspondente a 8,58 dias a mais de geração em relação ao sistema instalado. Portanto, a simulação computacional como ferramenta de otimização na geração de energia solar fotovoltaica mostrou ser uma prática de gestão de recursos eficaz aplicada no contexto urbano, de modo a contribuir para o atendimento dos objetivos do desenvolvimento sustentável da Agenda 2030.

Palavras-chave: Desenvolvimento sustentável. Energia renovável. Modelagem matemática.

\begin{abstract}
In recent years, economic and population growth has caused an increase in energy demand, which has consequently boosted the development and improvement of renewable energy systems and, especially in
\end{abstract}

HEI é mestre em Tecnologias Limpas, e-mail: eng.hugoimai@gmail.com

LFB é graduado em Engenharia Elétrica, e-mail: lucas.farinha.bosio@outlook.com

AASJ é mestrando em Inovações Tecnológicas, e-mail: eng.adrianojunior@gmail.com

LKB é mestranda em Tecnologias Limpas, e-mail: lilianberto_engenharia@hotmail.com

NUY é doutora em Engenharia Química, Pesquisadora, Prof. Dra., e-mail: natalia.yamaguchi@unicesumar.edu.br

LCSHR é doutora em Engenharia Química, Pesquisadora, Prof. Dra., e-mail: luciana.rezende@unicesumar.edu.br 
Brazil, of energy from photovoltaic panels. Given this scenario, this article aimed to optimize a company's photovoltaic solar energy generation system in order to contribute to the energy matrix and sustainable urban development through the application of mathematical modeling and simulation using the $M A T L A B 囚$ software (version 2018). The analysis of meteorological data and specifications of the module system were carried out for a period of 12 months. In total, three simulations were presented that optimized the installed system. However, it was possible to highlight the best model proposed, which resulted in 75,220 $\mathrm{kWh} \mathrm{/} \mathrm{year} \mathrm{of} \mathrm{energy} \mathrm{generation} \mathrm{and} \mathrm{provided} \mathrm{a} \mathrm{generation} \mathrm{gain} \mathrm{of} \mathrm{2.35 \%}$ corresponding to 8.58 more days of generation in relation to the installed system. Therefore, computer simulation as an optimization tool in the generation of photovoltaic solar energy demonstrated to be an effective resource management practice applied in the urban context, in order to contribute to meeting the sustainable development objectives of Agenda 2030.

Keywords: Sustainable development. Renewable energy. Mathematical modeling.

\section{Introdução}

Nos últimos anos, os fatores determinantes para o aumento da demanda de energia são o crescimento econômico e o populacional, principalmente da área urbana. Nejat et al. (2015) apontam que o consumo de energia residencial no contexto mundial cresceu $14 \%$ de 2000 a 2011. Cabe ressaltar que a capacidade instalada de geração elétrica no contexto mundial no período de 2011 a 2015 sofreu um aumento de 7,8\% (EPE, 2018).

No entanto, é notório que o crescimento econômico impulsionou a busca por fontes alternativas de energias mais limpas para atender a demanda energética, por intermédio das pressões entre os governos e as sociedades (Uzar, 2020). Sabe-se que, no período entre 2011 e 2015, o aumento da capacidade de fontes alternativas quase dobrou (EPE, 2018).

Ao reconhecer a dependência da gestão sustentável dos recursos naturais no desenvolvimento econômico, a Organização das Nações Unidas instituiu a Agenda 2030, que contém os 17 objetivos do desenvolvimento sustentável (ODS), em que o ODS 7 - assegurar energia limpa e acessível para todos está alinhado à perspectiva de crescimento do uso de energias renováveis (ONU, 2015).

Nesse contexto, a energia renovável é uma estratégia para a proteção do meio ambiente (Ike et al., 2020). Também, a inserção da geração de energia elétrica proveniente de fontes renováveis no setor urbano pode alcançar o desenvolvimento sustentável urbano e o equilíbrio energético (Fina et al., 2019), pois pode promover melhorias na sustentabilidade ambiental, o atendimento aos ODS e a mitigação das consequências ambientais (Ike et al., 2020), inclusive com relação aos efeitos negativos das emissões de carbono (Saidi \& Omri, 2020) causados pelas fontes de energia fósseis (Uzar, 2020).

Os estudos de Ike et al. (2020) apontaram que o consumo de energia renovável está diretamente ligado à redução de poluição nos países industrializados da Europa. Complementam Saidi \& Omri (2020) que a eficiência energética da energia renovável atenua as emissões de carbono e expande o crescimento econômico em curto e longo prazo.

Deste modo, o governo brasileiro tem alterado o seu foco com o propósito de fomentar o desenvolvimento de fontes de energias renováveis, inclusive a energia solar, que é considerada uma das mais promissoras e provém do recurso natural mais abundante da Terra (a radiação solar). Além disso, o Brasil está localizado em uma região favorável para o uso deste recurso (Faria et al., 2017). Por exemplo, em 2015, as fontes renováveis contribuíram com a matriz de energia primária no país, no entanto, 2,8\% inferior ao planejado no plano Brasil 2030 (Altoé et al., 2017).

Atualmente, a aplicação dos painéis fotovoltaicos para o fornecimento de energia em indústrias e comércios, em residências, em edifícios e em atividades dos setores agrícolas (Fina et al., 2019; Lima et al., 2017) se destaca pelo aproveitamento de áreas subutilizadas em espaços produtivos (Corcelli et al., 2019), geralmente aplicados em telhados (Costanzo et al., 2018). 
Dessa forma, o desenvolvimento e o melhoramento de energias mais limpas provenientes de fontes renováveis e com baixo ou nenhum impacto ambiental são impulsionados por pesquisas (Kumar et al., 2018), com o propósito de otimizar os sistemas de energia. Os modelos baseados em simulação com o intuito de aplicar no contexto das cidades mostram-se eficazes para otimizar a gestão urbana, como foi constatado nos estudos de Fioravanti \& Lima (2019).

Até o momento, a maior parte das pesquisas faz comparações da precisão das ferramentas de desempenho fotovoltaico individual e algumas não comparam com os dados de medição de sistemas fotovoltaicos reais. Poucos trabalhos estudaram a precisão dos modelos individuais para identificar uma configuração que minimiza o erro agregado do modelo de desempenho fotovoltaico como um todo (Roberts et al., 2017).

Nesse sentido, é fundamental a inserção de pesquisas com o intuito de alcançar um sistema operacional eficiente mediante a otimização da energia solar fotovoltaica a partir de um modelo matemático baseado no sistema de modulação fundamental para o funcionamento da resistência, entre outros. Dentre os programas computacionais utilizados para a modelagem matemática, destaca-se o MATLAB $^{\circledR}$, devido às vantagens de manipulação das equações de modelagem (Kumar et al., 2018).

Diante do exposto, o objetivo geral deste artigo foi otimizar a geração de energia solar fotovoltaica em um estabelecimento comercial, com a finalidade de contribuir com a matriz energética e o desenvolvimento sustentável urbano pela aplicação da modelagem matemática e simulação, com o uso do software MATLAB ${ }^{\circledR}$ (versão 2018), por meio da análise dos dados meteorológicos e das especificações do sistema de placas, por um período de 12 meses durante o ano de 2018.

\section{Revisão de literatura}

Nesta seção, a revisão de literatura é desenvolvida por meio da apresentação do estado da arte da energia fotovoltaica e da modelagem no contexto de gestão urbana, em que, primeiramente, são expostas as principais contribuições desde a descoberta do efeito da energia fotovoltaica até os dispositivos e as vantagens dos tempos atuais; em seguida, são apresentadas a aplicação de energia fotovoltaica no contexto urbano e a otimização do sistema por meio da modelagem e simulação.

\section{Estado da arte da energia fotovoltaica}

A descoberta do efeito da energia fotovoltaica foi datada em 1839 pelo físico francês Alexandre Edmond Becquerel (Dong et al., 2020). Becquerel (1839) observou a geração de corrente elétrica a partir da exposição à luz de dois eletrodos de prata ou platina em um eletrólito. Posteriormente, Adams \& Day (1877), ao fazerem o uso das características fotocondutoras do selênio, desenvolveram o primeiro dispositivo de estado sólido capaz de gerar uma diferença de potencial quando submetido à luz.

Outros autores (Lange, 1930; Schottky, 1930; Grondahl, 1933) investigaram os efeitos de células fotovoltaicas de selênio e óxido de cobre. Esses trabalhos levaram ao desenvolvimento de dispositivos, inclusive o medidor de exposição fotográfica (Kaushika et al., 2018; Treble, 1980). Entretanto, o marco inicial em termos de eficiência de célula fotovoltaica ocorreu na Idade Moderna. Chapin et al. (1954) criaram a primeira célula fotovoltaica de silício de junção p-n, que apresentou eficiência de apenas 6\%, porém 5,5\% maior em comparação com a eficiência das fotocélulas comercializadas até então. Ainda neste ano, Reynolds et al. (1954) desenvolveram um dispositivo similar com o uso de sulfeto de cádmio. Além disso, estes estudos foram aplicados e otimizados para o fornecimento de energia para satélites e naves espaciais (Tsai et al., 2018; Treble, 1980).

Anos depois, Nasledov e colaboradores (1962) observaram a radiação estimulada em semicondutores com o uso do espectro de eletroluminescência das junções p-n com base em arsenieto de gálio (GaAs). Esse estudo apresentou uma eficiência entre 6 e 8\%, valor recorde para a época (Mikhailova et al., 2019). 
É notório que os estudos sucessivos nesta área tiveram a finalidade de otimizar a eficiência energética. Por exemplo, Woodall \& Hovel (1972) desenvolveram a célula fotovoltaica de arsenieto de gálio de alta qualidade, que alcançou uma eficiência entre 19 e 25\%. Ainda na década de 1970, o interesse em energia fotovoltaica foi evidenciado com a crise do petróleo de 1973 e, desta forma, mereceu destaque na maioria dos programas de energia renovável (Treble, 1980).

Já na década de 1980, as preocupações ambientais e sociais pelo uso das fontes fósseis e das fontes nucleares favoreceram ainda mais o desenvolvimento de fontes renováveis para o fornecimento de uma energia mais sustentável. Deste modo, as pesquisas, as tecnologias e as indústrias deram prioridade ao desenvolvimento de novos materiais e dispositivos mais eficazes, e, por consequência, a otimização de processos e ampliação da energia fotovoltaica (Kazmerski, 1997).

A saber, Mitzi e colaboradores (1995) investigaram as propriedades optoeletrônicas de perovskitas orgânicas e inorgânicas, que foram utilizadas anos depois como sensibilizadoras de luz visível para células fotovoltaicas nos estudos de Kojima et al. (2009) e alcançaram uma eficiência de 3,8\% para a conversão de energia solar.

Kavlak et al. (2018) apontam que, entre 1980 e 2012, houve uma redução aproximada de 25\% dos custos dos módulos fotovoltaicos, devido ao aumento da eficiência e à substituição de materiais onerosos. No período de 2012 até 2019, os custos dos módulos fotovoltaicos reduziram ainda mais, em virtude da tecnologia de emissor passivo e célula traseira (PERC) (Green, 2019).

\section{Modelagem no contexto da gestão urbana}

As tecnologias de geração de energia com fontes renováveis encontram-se em expansão, principalmente no setor urbano com os painéis fotovoltaicos, devido à integração desta tecnologia em estruturas arquitetônicas, geralmente em telhados (Costanzo et al., 2018). Dessa forma, a tecnologia fotovoltaica colabora com o desenvolvimento urbano sustentável mediante aproveitamento de áreas subutilizadas em espaços produtivos (Corcelli et al., 2019).

A difusão dos sistemas fotovoltaicos pode ser aplicada em apartamentos, áreas históricas com fachadas ornamentais, áreas rurais, ou seja, em diversos contextos no setor urbano (Fina et al., 2019). Os estudos de Fina e colaboradores (2019) apontaram que os métodos de otimização podem possuir objetivos distintos e dependem dos consumidores, como, por exemplo, a minimização de custos e a maximização do autoconsumo. Consequentemente, promove melhorias na sustentabilidade ambiental, atendimento aos ODS e a mitigação das consequências ambientais (Ike et al., 2020).

Os algoritmos matemáticos contribuem para interligar as ferramentas de modelagem que incluem as variáveis climáticas locais e outros parâmetros para avaliar o máximo rendimento de superfícies por meio de simulações (Costanzo et al., 2018). Logo, é fundamental uma avaliação adequada dos sistemas de energia fotovoltaica para uma implementação com melhor desempenho e, por conseguinte, maior eficiência (Corcelli et al., 2019) e produção de energia (Costanzo et al., 2018).

A simulação de sistemas fotovoltaicos é útil para (i) executar análise detalhada do desempenho do sistema em condições reais de operação em campo; (ii) investigar o impacto de diferentes perfis de carga; (iii) verificar o dimensionamento do sistema; (iv) determinar o tamanho ideal dos componentes fotovoltaicos; (v) avaliar a viabilidade de um sistema fotovoltaico em termos de produção de energia e custo do ciclo de vida do sistema, e ainda (vi) verificar opções de otimização do processo para aumento de produção de energia (Mondol et al., 2007).

As simulações de rendimento de energia gerada resultam em definições de modelos de desempenho fotovoltaico, assim como Villalva et al. (2009) também verificaram. Os modelos de desempenho fotovoltaico são representações matemáticas que fazem a predição da geração de energia com base nas especificações do sistema (módulos fotovoltaicos, inversores, característica de instalação, etc.) e em dados meteorológicos (irradiação solar, temperatura ambiente, velocidade do vento, etc.). Estes modelos podem ser simplificados, baseados em suposições gerais sobre componentes do sistema e fatores de 
perda, ou mais complexos, conforme as informações fornecidas pelos fabricantes, os parâmetros estimados e os relacionamentos empíricos para alcançar resultados mais próximos da realidade (Connolly et al., 2010).

A modelagem e a simulação de um sistema fotovoltaico estão sujeitas a uma série de erros inevitáveis, com imprecisões derivadas das suposições feitas ao representar um sistema real com equações matemáticas. Para determinar a confiabilidade dos modelos de desempenho fotovoltaicos para a previsão do rendimento de energia, é necessário identificar e quantificar os erros introduzidos em cada etapa do modelo, o que pode ser realizado por simulações em computador (Richter et al., 2015).

Logo, é notório que a modelagem matemática por meio de simulações computacionais com o intuito de aplicar no contexto das cidades se mostra eficaz para contribuir para o planejamento urbano, como foi constatado nos estudos de Fioravanti \& Lima (2019). Além disso, é uma forma de acelerar a maior integração de energia renovável em áreas urbanas mediante otimização de sistemas de energia fotovoltaica, que traz o aumento no desempenho técnico, econômico e ambiental (Liu et al., 2020), e, por consequência, contribui para o alcance do desenvolvimento sustentável urbano e o equilíbrio energético (Fina et al., 2019).

\section{Metodologia}

Nesta seção, a metodologia e os dados utilizados para validar um modelo de desempenho fotovoltaico são descritos. Primeiramente, são apresentados o local de estudo e a obtenção diária dos dados durante os meses de janeiro e dezembro de 2018, para geração de energia, além dos dados meteorológicos para o mesmo período. Também é descrita a modelagem matemática para estimar a irradiância solar recebida no painel fotovoltaico e é indicada a quantidade de energia gerada pelo sistema fotovoltaico a partir desta irradiância solar. Então, os dados para a obtenção do potencial máximo de geração de energia do sistema implantado foram implementados com consideração de quatro variáveis: os módulos fotovoltaicos, os inversores de frequência, a orientação e a inclinação das placas. Durante a seção, a modelagem matemática é descrita de forma detalhada para avaliar os ângulos ideais de instalação das placas fotovoltaicas que estimem um bom rendimento energético para futuras adequações da edificação comercial em estudo.

\section{Local de estudo}

O sistema fotovoltaico, objeto de estudo deste trabalho, se encontra instalado em uma edificação comercial, na região norte do estado do Paraná, em um terreno de aproximadamente $6.000 \mathrm{~m}^{2}$ (Figura 1). Os módulos fotovoltaicos estão instalados na cobertura do edifício com $1.900 \mathrm{~m}^{2}$ e abrangem uma área de $320 \mathrm{~m}^{2}$, equivalente a $16,8 \%$ da área da cobertura.

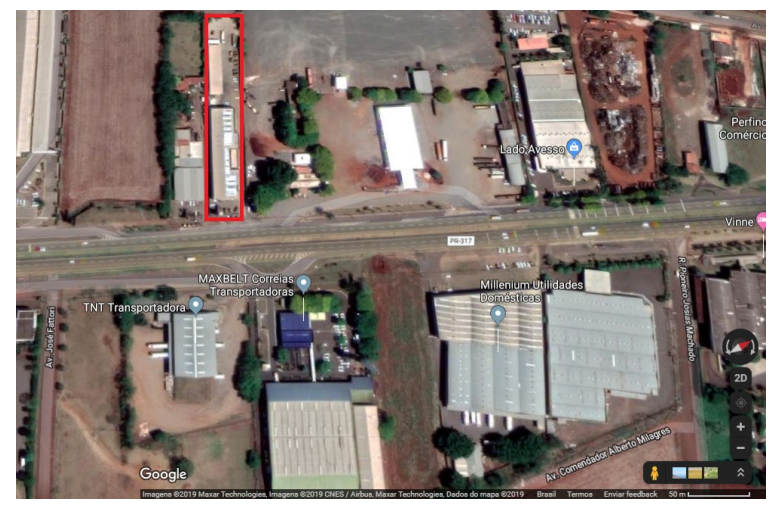

Figura 1 - Localização do sistema fotovoltaico instalado em estabelecimento comercial. Fonte: Google Maps, adaptada pelos autores (2019). 


\section{Obtenção dos dados para geração energética}

O projeto do sistema foi elaborado no software SOLergo ${ }^{\circledR}$ (versão 2017). Foram coletados os dados acerca das características de instalação do sistema de geração de energia solar, assim como foram identificados as marcas e os modelos de módulos solares e inversores de frequência utilizados na instalação, conforme apresentado na Tabela 1.

Tabela 1 - Dados das variáveis utilizadas para a execução do projeto (relatório SOLergo ${ }^{\circledR}$ )

\begin{tabular}{cc}
\hline Variáveis & Dados obtidos \\
\hline Latitude & $-023^{\circ}-27^{\prime}-24^{\prime \prime}$ \\
Longitude & $-051^{\circ}-59^{\prime}-23^{\prime \prime}$ \\
Albedo & $0,2 \%$ ao ano \\
Fabricante e modelo de módulos & CSI Canadian SolaR INC ${ }^{\circledR}-$ Max Power Max Power CS6X-325P* \\
Fabricante e modelo de inversores & Fronius International ${ }^{\circledR}-$ ECO $27.0-3-S^{* *}$ \\
Sombreamento & $0 \%$ \\
Ângulo de orientação das placas & $25^{\circ}$ \\
Ângulo de inclinação das placas & $7^{\circ}$ \\
Perdas totais & $20,4 \%$ \\
Latitude & $-023^{\circ}-27^{\prime}-24^{\prime \prime}$ \\
\hline
\end{tabular}

*160 módulos. ** 2 inversores. Fonte: Dados extraídos do relatório SOLergo® (Solergo, 2018).

Quanto às características dos equipamentos empregados no sistema, foram considerados 160 módulos fotovoltaicos, todos com as mesmas descrições técnicas, detalhadas na Tabela 2.

Tabela 2 - Informações técnicas do módulo fotovoltaico: CSI Canadian Solar INC ${ }^{\circledR}$ - Max Power Max Power CS6X-325P (Policristalino)

\begin{tabular}{cc}
\hline Parâmetros & Dados obtidos \\
\hline Número de células & 72 \\
Potência nominal (W) & 325 \\
Eficiência do módulo (\%) & 0,1694 \\
Tensão MPPT (V) & 37 \\
Tensão circuito aberto (V) & 45,5 \\
Corrente MPPT (A) & 8,78 \\
Corrente de curto circuito (A) & 9,34 \\
Coeficiente de temperatura de potência (\%) & $-0,0041$ \\
Coeficiente de temperatura de tensão de circuito aberto (\%) & $-0,0031$ \\
Coeficiente de temperatura de corrente de curto circuito (\%) & 0,00053 \\
\hline
\end{tabular}

Fonte: Informações extraídas da ficha de dados do CSI Canadian Solar INC ${ }^{\circledR}$ (CANADIAN, 2018).

As informações técnicas para os dois inversores da marca Fronius International ${ }^{\circledR}$, modelo ECO 27.0-3-S, apresentam as relações entre tensões e correntes fornecidas em potências máximas de $27.666 \mathrm{~W}$ para Corrente Contínua (CC) e de 27.000 W para Corrente Alternada (CA), com uma eficiência de carga máxima de 96,8\% e 98,1\% para os inversores com eficiência europeia ( $\eta \mathrm{EU}$ ) de 10 e $100 \% \mathrm{P}_{\mathrm{ac}, \mathrm{r}}$, respectivamente.

Ao ser implantado o sistema fotovoltaico, foram utilizados dois inversores de frequência da Fronius International ${ }^{\circledR}$, modelo ECO 27.0-3-S. Para que fosse possível a obtenção dos dados de geração do sistema instalado, foi necessário acessar o website solarweb. As informações obtidas foram divididas de forma diária e horária $(24$ h) nos 12 meses de 2018.

\section{Obtenção dos dados meteorológicos}

As fontes utilizadas para obtenção de dados meteorológicos necessários para a elaboração da modelagem matemática estão apresentadas na Tabela 3. 
Tabela 3 - Fontes de dados meteorológicos

\begin{tabular}{|c|c|c|}
\hline Parâmetros & Dados obtidos & Link \\
\hline INMET & $\begin{array}{l}\text { Temperatura instantânea do ar } \\
\text { Radiação solar }\end{array}$ & INMET (2019) \\
\hline NASA POWER & $\begin{array}{c}\text { Insolação solar horizontal } \\
\text { Índice de clareza da insolação }\end{array}$ & NASA POWER (2018) \\
\hline PYSOLAR & $\begin{array}{l}\text { Azimute } \\
\text { Elevação solar }\end{array}$ & PYSOLAR (2018) \\
\hline
\end{tabular}

Fonte: Autores (2019).

Os dados do Instituto Nacional de Meteorologia (INMET) foram encaminhados via correio eletrônico. Foram utilizadas as informações de temperatura instantânea do ar $\left({ }^{\circ} \mathrm{C}\right)$ e radiação solar $\left(\mathrm{kJ} / \mathrm{m}^{2}\right)$ descritas de forma diária e horária (período de 24 h) para o ano de 2018, referentes aos meses correntes de janeiro a dezembro.

As informações dos dados meteorológicos obtidas pela NASA (National Aeronautics and Space Administration) POWER (Prediction of Worldwide Energy Resources) foram obtidas por meio de endereço eletrônico, em dados diários no ano de 2018.

As informações referentes aos dados de posição solar foram acessadas pela plataforma digital PYSOLAR, no período de janeiro a dezembro de 2018. Esses dados são referentes ao azimute e à elevação solar, que foram monitorados ininterruptamente durante $24 \mathrm{~h}$ por dia.

\section{Desenvolvimento da modelagem matemática}

A modelagem matemática foi implementada na plataforma computacional Matlab ${ }^{\circledR}$ (versão 2018). A Figura 2 apresenta as etapas da metodologia que foram realizadas para a modelagem matemática. 0 estudo foi dividido basicamente em duas partes principais: (i) estimar a irradiância solar recebida no painel fotovoltaico, e (ii) estimar a quantidade de energia gerada pelo sistema fotovoltaico a partir da irradiância solar recebida.

No primeiro estágio, modelos para estimar a irradiância solar incidente no painel fotovoltaico foram empregados (modelos de combinação), enquanto, no segundo estágio, modelos matemáticos que estimam a energia gerada pelos módulos fotovoltaicos devido à irradiância do painel fotovoltaico foram implementados (modelo do módulo fotovoltaico). Numa terceira etapa secundária, incluem-se os sistemas de condicionamento de energia que captam a potência do painel fotovoltaico e o transformam na forma desejada, de acordo com as características da carga a ser atendida (modelo do inversor).

\section{Modelo de combinação}

A estimativa da irradiância solar incidente no painel fotovoltaico a partir dos dados da insolação solar horizontal envolve duas etapas: a decomposição da fração difusa e a transposição do painel fotovoltaico. Para cada uma dessas duas etapas, vários modelos foram propostos na literatura. No presente estudo, foram selecionados modelos típicos de decomposição e transposição para análise detalhada e, posteriormente, combinação em um único modelo para calcular a irradiância solar incidente no painel fotovoltaico. 0 CLIMED2 (Climatic Synthetic Time Series for the Mediterra nean Belt 2) é uma correlação horária (1997) que foi proposta por Miguel et al. (2001).

A Tabela 4 apresenta os modelos de decomposição e transposição selecionados para o presente estudo. 


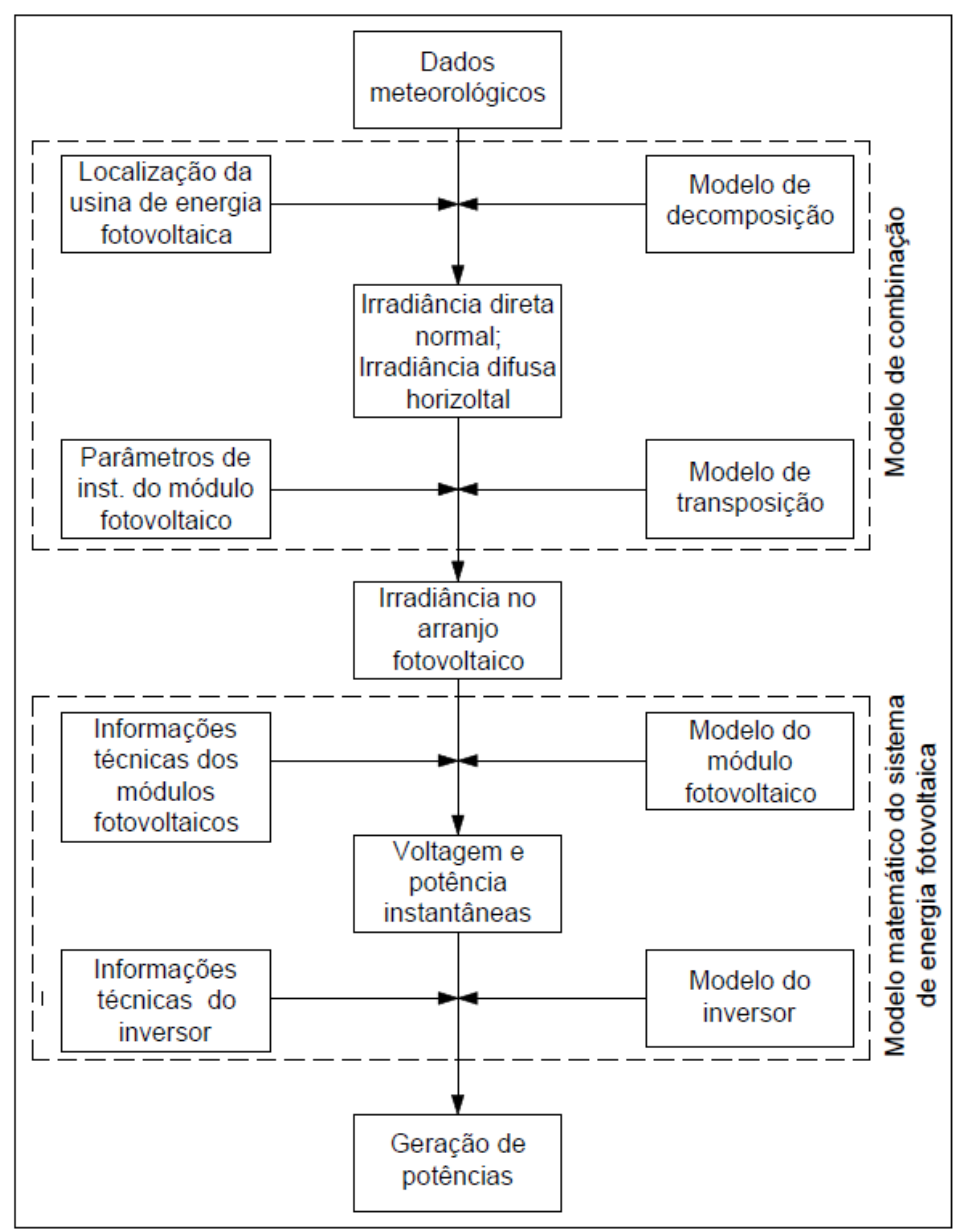

Figura 2 - Fluxograma para metodologia utilizada na modelagem matemática. Fonte: Autores (2019).

Tabela 4 - Modelos de decomposição e transposição selecionados para o presente estudo

\begin{tabular}{cc}
\hline Modelos de decomposição & Modelos de transposição \\
\hline Orgill \& Hollands (1977) & Liu \& Jordan (1963) \\
CLIMED2 & Tian et al. (2001) \\
Erbs et al. (1982) & Hay (1978) \\
Boland et al. (2001) & Reindl et al. (1990) \\
\hline
\end{tabular}

Fonte: Autores (2019).

\section{Modelo do módulo fotovoltaico}

O segundo estágio principal na modelagem de sistemas fotovoltaicos é determinar a produção de energia do módulo. 0 modelo de célula fotovoltaica proposto por Villalva et al. (2009) foi adotado no presente trabalho.

\section{Modelo do inversor}

Os inversores constituem uma peça chave em um sistema fotovoltaico, o que influencia em grande parte o desempenho do sistema. Observe-se, contudo, que estes representam uma pequena fração do custo total. Frequentemente, na modelagem de sistemas fotovoltaicos, a eficiência do inversor é representada como um fator constante, ou seja, assume-se que a eficiência do inversor é linear. 
No entanto, a eficiência do inversor, que indica qual a relação entre as potências de entrada e saída, depende da tensão. Esta, por sua vez, cujo nível de entrada influencia o rendimento do inversor, depende de uma adaptação entre a sua entrada e a sua saída (Roberts et al., 2017).

No presente estudo, foi implementado um modelo capaz de representar a eficiência do inversor em toda a faixa de operação simples, de integrar em ferramentas de simulação e de produzir resultados com boa precisão, conforme o modelo proposto por Notton et al. (2010).

\section{Validação do modelo matemático}

Para a validação do modelo matemático que visa otimizar a produção de energia com vistas ao aumento na matriz energética de um sistema fotovoltaico em operação, foram empregados dados obtidos diariamente durante o período de 12 meses. A precisão dos valores previstos com os modelos apresentados nas seções anteriores em relação aos dados obtidos das medições no sistema fotovoltaico em operação foi avaliada.

Também se estudou a precisão da combinação dos modelos de desempenho fotovoltaico como um todo, em que todos os modelos de desempenho fotovoltaico foram implementados na linguagem computacional Matlab ${ }^{\circledR}$. A adequação dos modelos para prever os valores medidos foi avaliada com uma série de métodos estatísticos amplamente citados (Roberts et al., 2017): coeficiente de determinação $\left(\mathrm{R}^{2}\right)$, raiz do erro quadrático médio (RMSE), raiz do erro quadrático médio relativo (rRMSE), tendência do erro médio (MBE) e tendência do erro médio relativo (rMBE).

\section{Otimização do sistema implantado}

Para a obtenção do potencial máximo de geração de energia do sistema implantado, foram realizadas simulações com o modelo matemático implementado e validado na seção anterior. Para a simulação, foram empregadas quatro variáveis fundamentais para a otimização: os módulos fotovoltaicos, os inversores de frequência, a orientação e a inclinação das placas (Figura 3). 0 processo de otimização foi dividido em duas etapas distintas. Na primeira etapa, foram substituídas as variáveis módulos fotovoltaicos e inversores de frequência; já na segunda etapa, foram substituídas as variáveis ângulo de orientação e inclinação dos módulos.

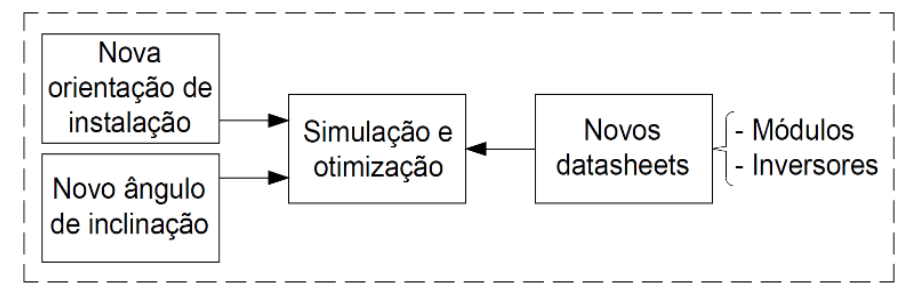

Figura 3 - Fluxograma para metodologia utilizada na otimização. Fonte: Autores (2019).

\section{Módulos fotovoltaicos e inversores}

Na primeira etapa, para otimizar o sistema de geração de energia fotovoltaica, a modelagem validada foi verificada quanto aos módulos fotovoltaicos e aos inversores de frequência. Foram utilizadas informações técnicas de cinco módulos fotovoltaicos e cinco inversores comerciais com a mesma potência da placa instalada ( $325 \mathrm{kWp}$ ). Os dados relativos aos módulos fotovoltaicos e aos inversores de frequência foram obtidos de acordo com os fabricantes.

A simulação para otimização foi realizada por meio do programa Matlab ${ }^{\circledR}$ com a finalidade de realizar todas as possíveis combinações entre os inversores e os módulos fotovoltaicos. Tanto os módulos 
fotovoltaicos quanto os inversores de frequência foram analisados com o intuito de obter a melhor associação para a geração de energia.

\section{Ângulo de orientação e inclinação}

Na segunda etapa, a modelagem, previamente validada, foi avaliada com relação à variação dos ângulos de orientação (azimute) e à inclinação dos módulos fotovoltaicos, com a finalidade de apresentar a melhor geração de energia.

Para a orientação dos módulos, considerou-se o ângulo zero $\left(0^{\circ}\right)$ como o norte verdadeiro, o que pode variar no sentido horário (norte-leste) com valores positivos e, no sentido anti-horário (norte-oeste), com valores negativos. Na simulação, o ângulo de orientação teve variação entre $-90^{\circ}$ (oeste) até $+90^{\circ}$ (leste), de $5^{\circ} \mathrm{em} 5^{\circ}$, e o ângulo de inclinação teve variação angular de $0^{\circ}$ até $60^{\circ}$, de $1^{\circ}$ em $1^{\circ}$.

A orientação e a inclinação dos módulos no sistema implantado, de acordo com o relatório SOLergo®, estão demostradas na Tabela $1, \operatorname{com} 25^{\circ}$ positivo e $7^{\circ}$ positivo, ambos ao norte, respectivamente.

Foram realizadas três simulações distintas: variação dos ângulos de orientação e inclinação; variação dos ângulos de orientação com o ângulo de inclinação fixo, e variação dos ângulos de inclinação com o ângulo de orientação fixo.

Desta forma, foram realizadas inúmeras combinações entre a variação dos ângulos de orientação e inclinação, para se encontrar a melhor combinação que culminasse na otimização da energia gerada. Os resultados podem ser observados nos gráficos de superfície apresentados na próxima seção.

\section{Resultados e discussões}

Os resultados da validação da modelagem matemática são apresentados segundo os dados obtidos por meio da simulação realizada conjuntamente com os modelos apresentados anteriormente. As análises estatísticas são discutidas de forma a se obter a melhor predição para a energia gerada. Todos os resultados deste trabalho são mostrados em termos percentuais com relação ao melhor desempenho obtido para cada um dos modelos simulados. A seção finaliza com a otimização da modelagem matemática no intuito de provocar um aumento na matriz energética do sistema fotovoltaico em operação.

\section{Validação da modelagem matemática}

A precisão dos valores previstos foi calculada com os modelos apresentados em relação aos dados medidos no sistema fotovoltaico em operação. Os diferentes modelos foram avaliados conjuntamente para se obter a melhor combinação.

A Tabela 5 apresenta os resultados da análise estatística comparativa da performance dos modelos fotovoltaicos estudados. A geração de energia foi simulada e o valor obtido foi comparado com o medido no sistema implantado.

Em termos de bem, o erro dos modelos varia de $-7,097 \mathrm{~W} / \mathrm{m}^{2}(-3,604 \% \mathrm{rMBE})$ para o modelo de Boland et al. (2001) e Hay (1978) a 13,538 W/m² (6,875\% rMBE) para o modelo de Erbs et al. (1982) e de Liu \& Jordan (1963), enquanto que, em termos de RMSE, o erro variou de 29,604 (15,034\% rRMSE) para o modelo de Orgill \& Hollands (1977) a 38,711 (19,659\% rRMSE) para o modelo de Boland et al. (2001) e Hay (1978). O R² variou de 0,7358 para o modelo de Boland et al. (2001) e de Hay (1978) a 0,8455 para o modelo de Orgill \& Hollands (1977). 
Tabela 5 - Análise estatística comparativa dos modelos de performance fotovoltaica implementados em relação aos dados do sistema instalado, combinação do modelo de decomposição + modelo de transposição + modelo do módulo fotovoltaico + modelo do inversor

\begin{tabular}{|c|c|c|c|c|c|c|c|c|}
\hline $\begin{array}{c}\text { Modelo } \\
\text { decomposição }\end{array}$ & $\begin{array}{c}\text { Modelo } \\
\text { transposição }\end{array}$ & $\begin{array}{l}\text { Modelo do } \\
\text { módulo } \\
\text { fotovoltaico }\end{array}$ & $\begin{array}{l}\text { Modelo do } \\
\text { inversor }\end{array}$ & $\mathbf{R}^{2}$ & $\begin{array}{l}\text { RMSE } \\
\left(W / m^{2}\right)\end{array}$ & $\begin{array}{l}\text { rRMSE } \\
\text { (\%) }\end{array}$ & $\begin{array}{l}\text { bem } \\
\left(W / m^{2}\right)\end{array}$ & $\begin{array}{l}\mathrm{rMBE} \\
(\%)\end{array}$ \\
\hline $\begin{array}{l}\text { Orgill \& Hollands } \\
\text { (1977) }\end{array}$ & Tian et al. (2001) & \multirow{16}{*}{$\begin{array}{l}\text { Villalva et al. } \\
\text { (2009) }\end{array}$} & \multirow{16}{*}{$\begin{array}{l}\text { Notton et al. } \\
(2010)\end{array}$} & 0,8455 & 29,6038 & 15,0339 & 10,1088 & 5,1336 \\
\hline CLIMED2 & Tian et al. (2001) & & & 0,8439 & 29,7560 & 15,1113 & 10,3470 & 5,2546 \\
\hline Erbs et al. (1982) & Tian et al. (2001) & & & 0,8422 & 29,9154 & 15,1922 & 10,4540 & 5,3089 \\
\hline $\begin{array}{c}\text { Orgill \& Hollands } \\
\text { (1977) }\end{array}$ & $\begin{array}{l}\text { Liu \& Jordan } \\
\text { (1963) }\end{array}$ & & & 0,8368 & 30,4257 & 15,4513 & 13,3623 & 6,7858 \\
\hline CLIMED2 & $\begin{array}{l}\text { Liu \& Jordan } \\
\text { (1963) }\end{array}$ & & & 0,8356 & 30,5409 & 15,5098 & 13,4621 & 6,8366 \\
\hline Erbs et al. (1982) & $\begin{array}{l}\text { Liu \& Jordan } \\
\text { (1963) }\end{array}$ & & & 0,8344 & 30,6451 & 15,5627 & 13,5381 & 6,8751 \\
\hline $\begin{array}{c}\text { Orgill \& Hollands } \\
\text { (1977) }\end{array}$ & $\begin{array}{l}\text { Reindl et al. } \\
\text { (1990) }\end{array}$ & & & 0,8259 & 31,4219 & 15,9572 & $-5,4337$ & 2,7594 \\
\hline Erbs et al. (1982) & $\begin{array}{l}\text { Reindl et al. } \\
\text { (1990) }\end{array}$ & & & 0,8256 & 31,4566 & 15,9748 & $-3,7193$ & 1,8888 \\
\hline $\begin{array}{c}\text { Orgill \& Hollands } \\
\text { (1977) }\end{array}$ & Hay (1978) & & & 0,8246 & 31,5392 & 16,0167 & $-5,7185$ & 2,9041 \\
\hline Erbs et al. (1982) & Hay (1978) & & & 0,8244 & 31,5592 & 16,0269 & $-3,9862$ & 2,0243 \\
\hline CLIMED2 & $\begin{array}{l}\text { Reindl et al. } \\
\text { (1990) }\end{array}$ & & & 0,8202 & 31,9337 & 16,2171 & $-6,2211$ & 3,1593 \\
\hline \multirow{2}{*}{$\begin{array}{c}\text { CLIMED2 } \\
\text { Boland et al. } \\
\text { (2001) }\end{array}$} & Hay (1978) & & & 0,8188 & 32,0571 & 16,2798 & $-6,5025$ & 3,3022 \\
\hline & Tian et al. (2001) & & & 0,7541 & 37,3493 & 18,9673 & 7,5566 & 3,8375 \\
\hline $\begin{array}{l}\text { Boland et al. } \\
\text { (2001) }\end{array}$ & $\begin{array}{l}\text { Liu \& Jordan } \\
\text { (1963) }\end{array}$ & & & 0,7460 & 37,9565 & 19,2757 & 10,6954 & 5,4315 \\
\hline \multirow{2}{*}{$\begin{array}{c}\text { Boland et al. } \\
\text { (2001) } \\
\text { Boland et al. } \\
\text { (2001) }\end{array}$} & $\begin{array}{l}\text { Reindl et al. } \\
\text { (1990) }\end{array}$ & & & 0,7370 & 38,6248 & 19,6151 & $-6,8261$ & 3,4665 \\
\hline & Hay (1978) & & & 0,7358 & 38,7109 & 19,6588 & $-7,0974$ & 3,6043 \\
\hline
\end{tabular}

Fonte: Autores (2018).

De maneira geral, observou-se que os modelos de sistema fotovoltaico que incorporam o modelo de transposição de Reindl et al. (1990) e Hay (1978) tenderam a subestimar a energia anual produzida, já que o valor de MBE e rMBE foram negativos para estes modelos, enquanto os modelos de transposição de Liu \& Jordan (1963) e de Tian et al. (2001) superestimaram o rendimento anual da energia produzida, com os valores MBE e rMBE positivos. Este resultado era esperado, visto que os métodos anisotrópicos consideram o céu repleto de nuvens; portanto, estimam uma menor quantidade de irradiância incidente e, consequentemente, uma menor quantidade de energia produzida.

0 modelo de céu anisotrópico considera que a intensidade da radiação difusa não é uniforme ao longo do céu, com a existência de efeitos pontuais do horizonte e circunvizinho ao sol, enquanto que os modelos isotrópicos consideram o céu como uma fonte uniforme de irradiância difusa. 0 modelo isotrópico foi desenvolvido inicialmente para aplicação em coletores solares para aquecimento e tem origem anterior ao uso em grande escala de painéis fotovoltaicos (Lee et al., 2011).

Uma diferença percentual média de $5 \%$ dos resultados estimados para o rendimento energético real é considerada aceitável para estudos de viabilidade (Lee et al., 2011). No entanto, a incerteza combinada do rendimento anual de um sistema fotovoltaico pode subir até 8,7\% para anos individuais e até 7,9\% para o rendimento médio ao longo da vida útil do sistema (Thevenard \& Pelland, 2013). Richter et al. (2015) relataram que o uso dos melhores algoritmos de desempenho fotovoltaico disponíveis resulta em incertezas da ordem de $\pm 3,75 \%$ a $\pm 5 \%$, sem considerar as incertezas não dependentes da temperatura presentes no sistema. De acordo com os resultados mostrados na Tabela 5, todos os modelos apresentaram um nível de precisão próximo de $\pm 5 \%$ rMBE. 
Uma série de erros na cadeia de modelagem pode contribuir para o desvio das estimativas dos valores medidos. A primeira fonte de erro deriva dos algoritmos matemáticos subjacentes usados nas simulações. Isso inclui o erro dos modelos para estimar a irradiância solar incidente no painel fotovoltaico (IPV), o erro dos modelos de módulos fotovoltaicos (que inclui a estimativa da temperatura da célula solar) e o erro dos modelos do inversor (Roberts et al., 2017).

Uma abordagem geral para validar um modelo de simulação de sistema fotovoltaico é gerar um gráfico de dispersão da potência prevista vs. potência medida para o intervalo de tempo (12 meses, no presente estudo).

O gráfico de dispersão para o modelo de desempenho de melhor resultado dos autores estudados, Orgill \& Hollands (1977), Tian et al. (2001), para os sistemas fotovoltaicos apresentados na Tabela 5 está ilustrado na Figura 4. A linha tracejada vermelha tem uma inclinação de 1 e representa a igualdade exata entre valores medidos e modelados. Portanto, os pontos acima da linha indicam que o modelo superestimou a energia da matriz e os pontos abaixo da linha indicam que o modelo subestimou a energia.

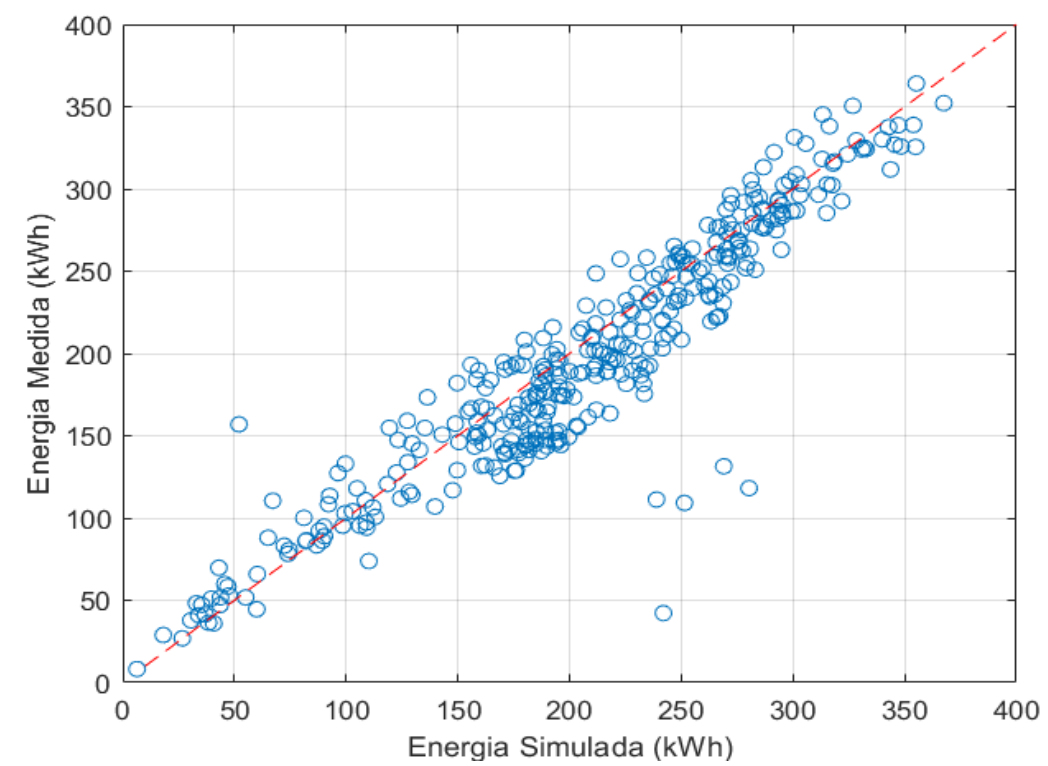

Figura 4 - Energia medida vs. simulada relativa total para o melhor modelo referente ao ano de 2018. Fonte: Autores (2019).

A dispersão de pontos é maior para níveis mais altos de potência fotovoltaica (>150 kW). Isso indica que os modelos falham na representação com precisão do comportamento do sistema fotovoltaico durante períodos de altos níveis de irradiância. Em níveis mais baixos de produção de energia $(<150 \mathrm{~kW})$, os modelos tendem a subestimar a potência, dado que os pontos ficam acima da linha da inclinação 1. Esse efeito é menos evidente conforme aumenta os níveis de irradiância ( $>150 \mathrm{~kW})$, visto que os pontos ficam abaixo da linha da inclinação 1, superestimou a potência (Roberts et al., 2017).

\section{Otimização do sistema implantado}

Para a otimização do sistema implantado, foram empregadas duas ações distintas na simulação dos dados. Na primeira, o modelo validado com substituição dos módulos fotovoltaicos e inversores para verificação da energia produzida instalada, e na segunda, com substituição dos ângulos de orientação e inclinação dos módulos. Ambas as situações contribuíram para o melhor aproveitamento do sistema instalado e, consequentemente, para o desenvolvimento sustentável. 


\section{Módulos fotovoltaicos e inversores}

Os resultados obtidos para a otimização do sistema para diferentes módulos fotovoltaicos e inversores estão apresentados na Tabela 6.

Tabela 6 - Otimização de simulação de energia anual produzida para diferentes módulos fotovoltaicos e inversores

\begin{tabular}{|c|c|c|c|c|}
\hline $\begin{array}{c}\text { Marca e } \\
\text { Modelo de } \\
\text { módulo } \\
\text { fotovoltaico }\end{array}$ & Marca e Modelo de inversor & $\begin{array}{l}\text { Energia } \\
\text { produzida total } \\
\text { (kWh) }\end{array}$ & $\begin{array}{l}\text { Taxa de variação } \\
\text { na produção de } \\
\text { energia (kWh) }\end{array}$ & $\begin{array}{c}\text { Taxa de variação } \\
\text { na produção de } \\
\text { energia (\%) }\end{array}$ \\
\hline & Fronius International ${ }^{\circledR}$ Eco $27.0-3-S$ & 73493,04 & 0 & 0 \\
\hline CANADIAN & ABB Pro-33.0-TL & 73886,71 & 393,67 & 0,54 \\
\hline SOLAR INC ${ }^{\circledR}$ & ABB Trio-20.0/27.6-TL & 73498,66 & 5,62 & 0,01 \\
\hline \multirow[t]{4}{*}{ CS6X-325P } & SUNGROW ${ }^{\circledR}$ SG33CX & 73223,86 & $-269,17$ & $-0,37$ \\
\hline & SUNGROW ${ }^{\circledR}$ SG36KTL-M & 73583,19 & 90,15 & 1,12 \\
\hline & Fronius International ${ }^{\circledR}$ ECo $27.0-3-S$ & 74740,13 & 1247,09 & 1,70 \\
\hline & ABB Pro-33.0-TL & 75143,24 & 1650,20 & 2,25 \\
\hline \multirow[t]{5}{*}{$\mathrm{BYD}^{\circledR} 325 \mathrm{P} 6 \mathrm{D}-36$} & ABB Trio-20.0/27.6-TL & 74744,95 & 1251,91 & 1,70 \\
\hline & SUNGROW ${ }^{\circledR}$ SG33CX & 74478,46 & 985,42 & 1,34 \\
\hline & SUNGROW® ${ }^{\circledR} G 36 K T L-M$ & 74837,43 & 1344,39 & 1,83 \\
\hline & Fronius International ${ }^{\circledR}$ ECo 27.0-3-S & 74694,29 & 1201,25 & 1,63 \\
\hline & ABB Pro-33.0-TL & 75096,85 & 1603,81 & 2,18 \\
\hline \multirow[t]{4}{*}{ BYD ${ }^{\circledR} 325 \mathrm{P} 6 \mathrm{~K}-36$} & ABB Trio-20.0/27.6-TL & 74699,16 & 1206,12 & 1,64 \\
\hline & SUNGROW ${ }^{\circledR}$ SG33CX & 74432,18 & 939,14 & 1,28 \\
\hline & SUNGROW® SG36KTL-M & 74791,17 & 1298,13 & 1,76 \\
\hline & Fronius International ${ }^{\circledR}$ Eco $27.0-3-S$ & 73380,83 & $-112,21$ & $-0,15$ \\
\hline Q Cells & ABB Pro-33.0-TL & 73773,85 & 280,82 & 0,38 \\
\hline Q.POWER L-G5 & ABB Trio-20.0/27.6-TL & 73386,51 & $-106,53$ & $-0,14$ \\
\hline \multirow[t]{3}{*}{325} & SUNGROW ${ }^{\circledR}$ SG33CX & 73111,13 & $-381,90$ & $-0,52$ \\
\hline & SUNGROW® ${ }^{\circledR} G 36 K T L-M$ & 73470,49 & $-22,55$ & $-0,03$ \\
\hline & Fronius International ${ }^{\circledR}$ ECo $27.0-3-S$ & 72867,63 & $-625,41$ & $-0,85$ \\
\hline \multirow{4}{*}{$\begin{array}{c}\text { Q Cells } \\
\text { Q.POWER L- } \\
\text { G5.2 } 325\end{array}$} & ABB Pro-33.0-TL & 73256,64 & $-236,40$ & $-0,32$ \\
\hline & ABB Trio-20.0/27.6-TL & 72873,65 & $-619,39$ & $-0,84$ \\
\hline & SUNGROW ${ }^{\circledR}$ SG33CX & 72594,68 & $-898,36$ & $-1,22$ \\
\hline & SUNGROW ${ }^{\circledR}$ SG36KTL-M & 72954,22 & $-538,82$ & $-0,73$ \\
\hline
\end{tabular}

Fonte: Autores (2018).

Os casos em que são apresentados valores negativos decorrem da energia produzida simulada total ser menor do que a energia produzida simulada pelo modelo validado. Dez simulações obtiveram resultados negativos e 15 , resultados positivos, ou seja, $60 \%$ apresentou energia produzida total superior à energia produzida instalada. Em geral, pode-se observar que os resultados que obtiveram energia produzida maior do que a energia instalada foram obtidos devido à maior eficiência do módulo da marca BYD $^{\circledR}$. Da mesma maneira, os inversores que obtiveram maior energia produzida total simulada foram SUNGROW ${ }^{\circledR}$ SG36KTL-M e ABB Pro-33.0-TL, pois estes apresentam maior eficiência a $10 \%$ e $100 \%$ da carga máxima, respectivamente.

Ao verificar o aumento da taxa de energia produzida, o melhor resultado foi de $2,25 \%$, correspondente a 1.650,20 kWh, resultado da combinação entre o módulo BYD 325P6D-36 e o inversor ABB Pro-33.0-TLOUTD. Com isto, é possível concluir que se a energia anual produzida pelo sistema é de 73.493,04 kWh, o modelo proposto proporcionou um ganho que corresponde a 8,2 dias a mais de geração.

\section{Ângulo de orientação e inclinação}

Na variação angular de inclinação e de orientação, por meio das ferramentas gráficas do Matlab ${ }^{\circledR}$, foi possível encontrar informações numéricas relacionadas ao ponto de energia simulada, de acordo com o descrito na metodologia. A Figura 5 apresenta quatro pontos distintos: [A]; [B]; [C]; [D]. 


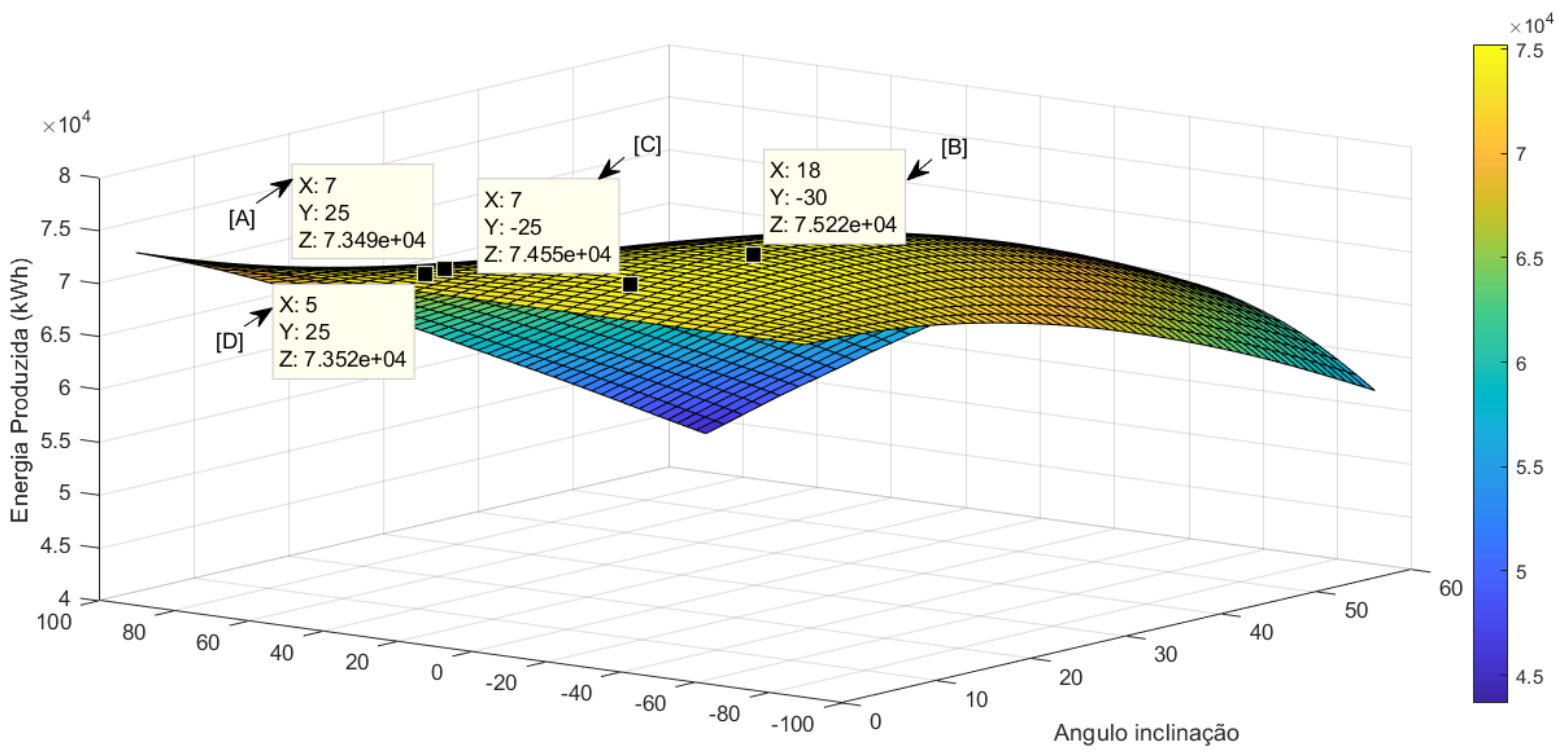

Ângulo orientação (Azimute)

Figura 5 - Superfície de resposta de otimização: variação do ângulo de inclinação e de orientação. [A] Geração do sistema implantado; [B] Máxima geração do sistema otimizado; [C] Geração do sistema otimizado: variação do ângulo de inclinação; [D] Geração do sistema otimizado: variação do ângulo de orientação. Fonte: Autores (2019).

Ao considerar a energia gerada pelo sistema implantado por meio da simulação do modelo validado, tem-se uma geração de energia anual de $73.493,04 \mathrm{kWh}$, de acordo com o ponto [A]. Este, assim como na seção anterior ("Módulos fotovoltaicos e inversores"), foi utilizado para comparar as três simulações de otimização.

Na primeira simulação, a fim de encontrar o ponto de máxima geração do sistema otimizado, foram variados ambos os ângulos de orientação e inclinação dos módulos fotovoltaicos. A partir de 11.041 combinações, foi encontrado o valor indicado no ponto [B], $75.220 \mathrm{kWh}$, com ângulo de inclinação de $18^{\circ}$ e orientação de $-30^{\circ}$. Ao comparar com a energia indicada no ponto [A], foi identificada uma diferença de $1.726,96 \mathrm{kWh}$, valor este que condiz com um aumento anual de geração de 2,35\%, compatível com 8,58 dias/ano a mais de geração do sistema instalado.

Para uma análise mais aprofundada, com a finalidade de entender o efeito dos ângulos de orientação e inclinação individualmente, foram realizadas a segunda e a terceira simulações. Em ambas, apenas um dos ângulos (orientação ou inclinação) foi alterado. No segundo caso, fixou-se o ângulo de inclinação e variou-se o ângulo de orientação, culminando em 181 combinações. 0 resultado pode ser encontrado na Figura 5, de acordo com o ponto [C], $74.550 \mathrm{kWh}$, com ângulo de inclinação de $7^{\circ}$ e de orientação de $25^{\circ}$. Ao comparar com a energia indicada no ponto [A], foi encontrada uma diferença de $1.056,96 \mathrm{kWh}$, valor este que condiz com um aumento anual de geração de 1,44\%, compatível com 5,24 dias/ano a mais de geração do sistema instalado. Na Figura 6, são mostrados os pontos no gráfico de otimização.

Após duas simulações, para o terceiro caso, fixou-se o ângulo de orientação e variou-se o ângulo de inclinação, culminando em 61 combinações entre eles. De acordo com a Figura 5, o resultado pode ser encontrado no ponto [D], $73.520 \mathrm{kWh}$, com ângulo de inclinação de $5^{\circ}$ e de orientação de $25^{\circ}$. Ao comparar com a energia indicada no ponto [A], foi encontrada uma diferença de $1.056,96 \mathrm{kWh}$, valor este que condiz com um aumento anual de geração de 0,04\%, compatível com 0,13 dia/ano a mais de geração do sistema instalado. Na Figura 7, são mostrados os pontos no gráfico de otimização. 


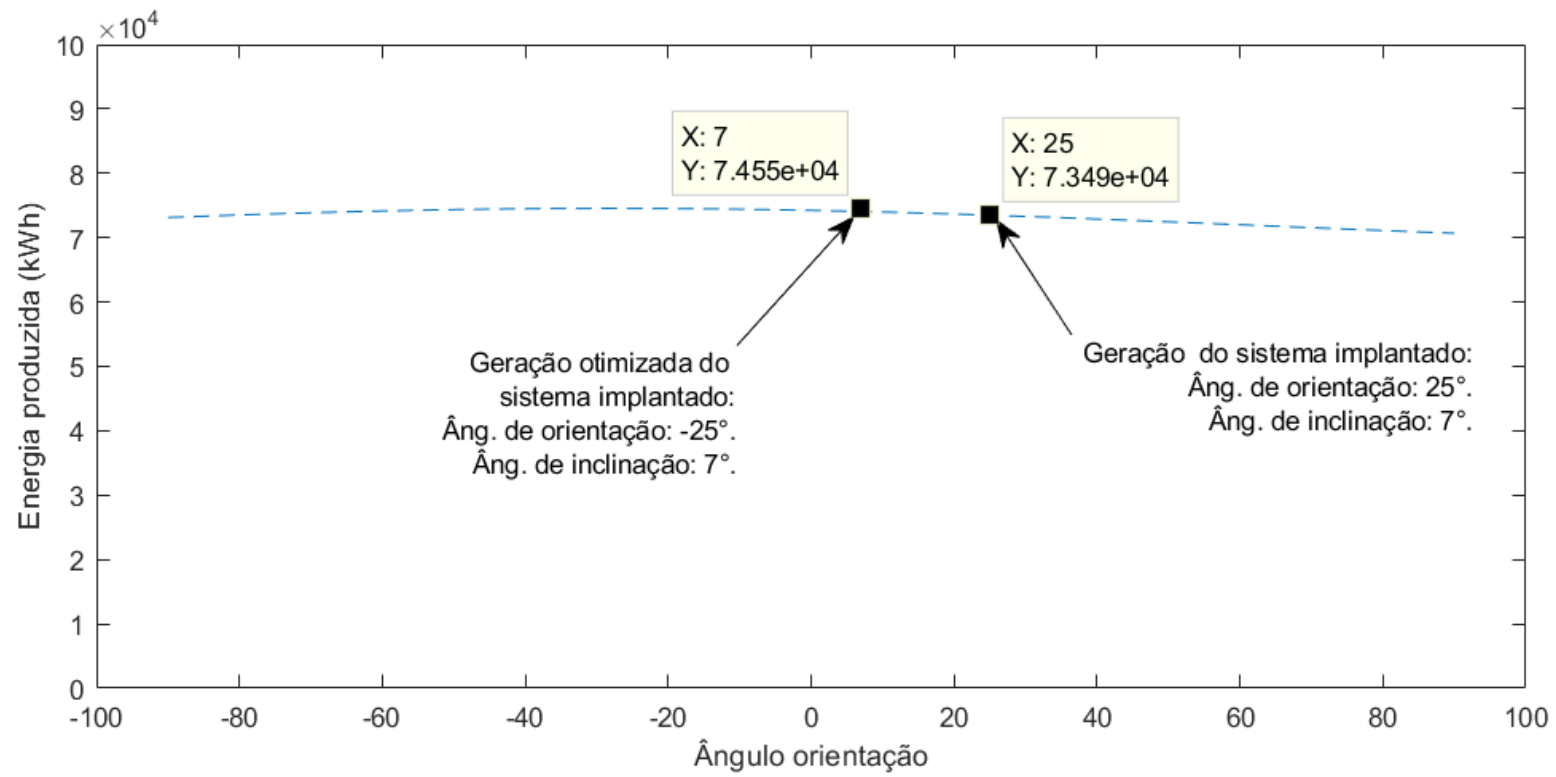

Figura 6 - Energia gerada vs. variação do ângulo de orientação - ângulo de inclinação fixo em $7^{\circ}$. Fonte: Autores (2019).

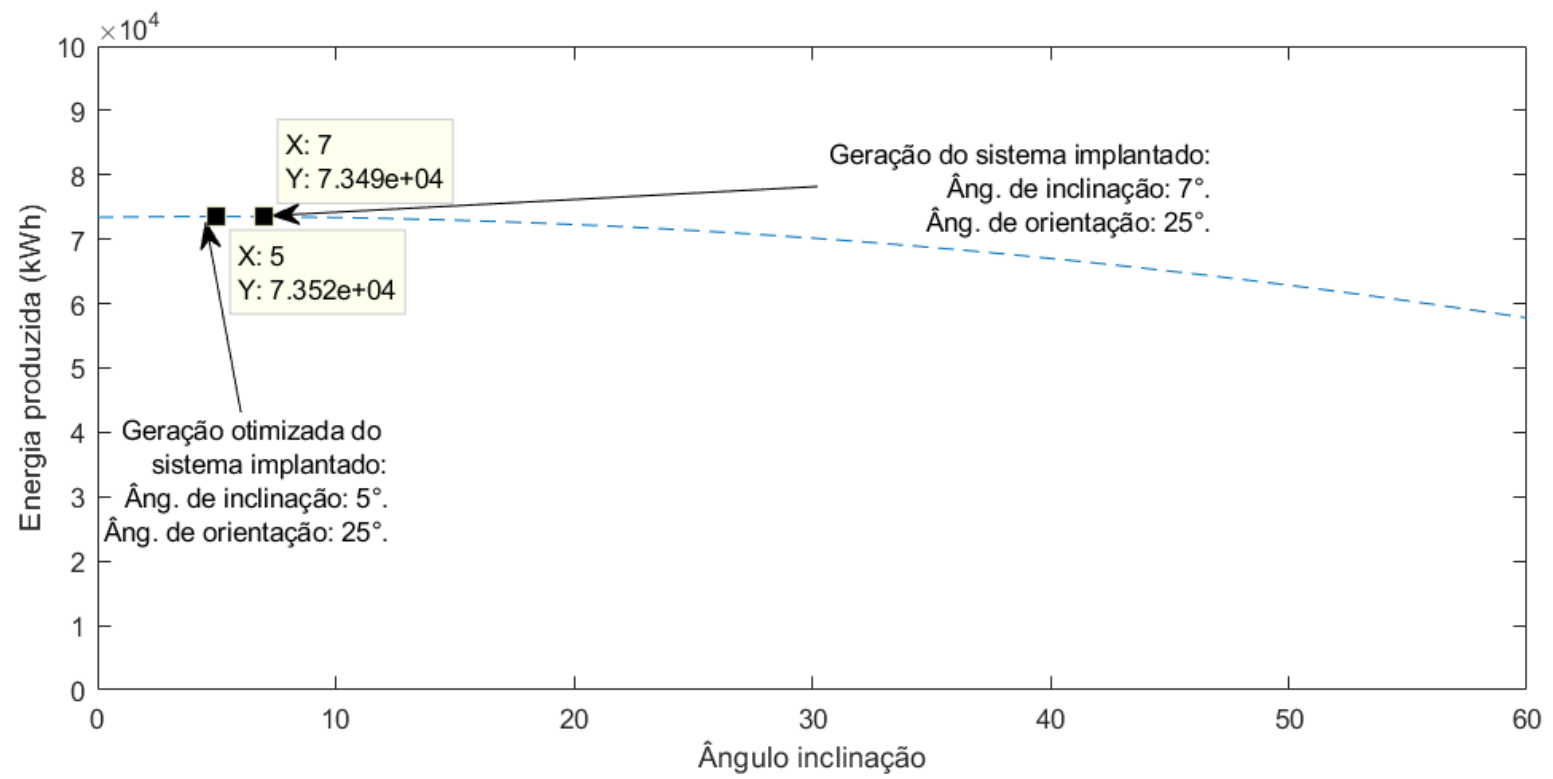

Figura 7 - Energia gerada vs. variação do ângulo de inclinação - ângulo de orientação fixo em $25^{\circ}$. Fonte: Autores (2019).

Dentre as três simulações em que o foco da otimização são os ângulos de inclinação e orientação, foi possível verificar que a variação de ambos os ângulos obteve um aumento maior da geração, resultando em 75,220 kWh/ano.

Contudo, se considerar apenas a variação de um dos ângulos, o de orientação pode ser mais viável, haja vista que a variação do ângulo de inclinação não contribuiu para um aumento considerável na produção de energia.

\section{Conclusões}

Neste trabalho, 16 modelos matemáticos foram validados por meio do software Matlab $^{\circledR}$ a partir de dados meteorológicos e dados de um sistema de geração de energia solar fotovoltaico instalado em um 
estabelecimento comercial. A partir da modelagem, a otimização foi realizada para diferentes módulos e inversores, além de novos ângulos de inclinação e orientação das placas, o que possibilitou gerar resultados otimizados.

O modelo que apresentou melhores resultados foi o modelo que inclui os autores, Orgill \& Hollands (1977), Tian et al. (2001), Villalva et al. (2009) e Notton et al. (2010), que resultou em $75.220 \mathrm{kWh} / \mathrm{ano}$ de geração de energia e proporcionou um ganho de geração de 2,35\%, correspondente a 8,58 dias a mais de geração em relação ao sistema instalado.

Portanto, a simulação computacional como ferramenta de otimização na geração de energia solar fotovoltaica mostrou ser uma prática de gestão de recursos eficaz, aplicada no contexto urbano. Certamente, essa prática sustentável pode ser aplicada em outras áreas das cidades, como, por exemplo, em casas e apartamentos, e até em dimensões maiores, como grandes indústrias, de modo a contribuir para o planejamento urbano e o atendimento dos objetivos do desenvolvimento sustentável da Agenda 2030, em especial, o ODS 7, que trata da meta de assegurar energia limpa e acessível para todos.

\section{Referências}

Adams, W. G., \& Day, R. E. (1877). IX. The action of light on selenium. Philosophical Transactions of the Royal Society of London, 167, 313-349. http://dx.doi.org/10.1098/rstl.1877.0009.

Altoé, L., Costa, J. M., Oliveira, D., Fo., Martinez, F. J. R., Ferrarez, A. H., \& Viana, L. D. A. (2017). Políticas públicas de incentivo à eficiência energética. Estudos Avançados, 31(89), 285-297. http://dx.doi.org/10.1590/s010340142017.31890022.

Becquerel, M. E. (1839). Mémoire sur les effets électriques produits sous l'influence des rayons solaires (Vol. 9). Paris: l'Académie des sciences. Comptes rendus hebdomadaires des séances.

Boland, J., Scott, L., \& Luther, M. (2001). Modelling the diffuse fraction of global solar radiation on a horizontal surface. Environmetrics, 12(2), 103-116. http://dx.doi.org/10.1002/1099-095X(200103)12:2<103:AIDENV447>3.0.CO;2-2.

Canadian Solar Datasheet- CANADIAN. (2018). Recuperado em 30 de Janeiro de 2019, de https://www.canadiansolar.com/downloads/datasheets/v5.4/Canadian_Solar-Datasheet-.

Connolly, D., Lund, H., Mathiesen, B. V., \& Leahy, M. (2010). A review of computer tools for analysing the integration of renewable energy into various energy systems. Applied Energy, 87(4), 1059-1082.

http://dx.doi.org/10.1016/j.apenergy.2009.09.026.

Corcelli, F., Fiorentino, G., Petit-Boix, A., Rieradevall, J., \& Gabarrell, X. (2019). Transforming rooftops into productive urban spaces in the Mediterranean. An LCA comparison of agri-urban production and photovoltaic energy generation. Resources, Conservation and Recycling, 144, 321-336.

http://dx.doi.org/10.1016/j.resconrec.2019.01.040.

Costanzo, V., Yao, R., Essah, E., Shao, L., Shahrestani, M., Oliveira, A. C., Araz, M., Hepbasli, A., \& Biyik, E. (2018). A method of strategic evaluation of energy performance of Building Integrated Photovoltaic in the urban context. Journal of Cleaner Production, 184, 82-91. http://dx.doi.org/10.1016/j.jclepro.2018.02.139.

Chapin, D. M., Fuller, C. S., \& Pearson, G. L. (1954). A new silicon p-n junction photocell for converting solar radiation into electrical power. Journal of Applied Physics, 25(5), 676-677. http://dx.doi.org/10.1063/1.1721711.

Dong, C. R., Wang, Y., Zhang, K., \& Zeng, H. (2020). Halide perovskite materials as light harvesters for solar energy conversion. EnergyChem, 2, 100026. http://dx.doi.org/10.1016/j.enchem.2020.100026.

Empresa de Pesquisa Energética - EPE. (2018). Anuário Estatístico de Energia Elétrica 2018 no Ano Base de 2017. Rio de Janeiro: EPE. Recuperado em 19 de abril de 2020, de www.epe.gov.br 
Erbs, D. G., Klein, S. A., \& Duffie, J. A. (1982). Estimation of the diffuse radiation fraction for hourly, daily and monthly-average global radiation. Solar Energy, 28(4), 293-302. http://dx.doi.org/10.1016/0038-092X(82)903024.

Faria, H., Jr., Trigoso, F. B., \& Cavalcanti, J. A. (2017). Review of distributed generation with photovoltaic grid connected systems in Brazil: challenges and prospects. Renewable \& Sustainable Energy Reviews, 75, 469-475. http://dx.doi.org/10.1016/j.rser.2016.10.076.

Fina, B., Auer, H., \& Friedl, W. (2019). Profitability of PV sharing in energy communities: use cases for different settlement patterns. Energy, 189, 116148. http://dx.doi.org/10.1016/j.energy.2019.116148.

Fioravanti, R. D., \& Lima, O. F., Jr. (2019). Modelo para análise ex ante de políticas de logística urbana baseadas em centros de distribuição urbanos: uma abordagem utilizando dinâmica de sistemas. urbe. Urbe. Revista Brasileira de Gestão Urbana, 11, e20170170. http://dx.doi.org/10.1590/2175-3369.011.002.A003.

Green, M. A. (2019). How did solar cells get so cheap? Joule, 3(3), 631-633.

http://dx.doi.org/10.1016/j.joule.2019.02.010.

Grondahl, L. O. (1933). The copper-cuprous-oxide rectifier and photoelectric cell. Reviews of Modern Physics, 5(2), 141. http://dx.doi.org/10.1103/RevModPhys.5.141.

Hay, J. E. (1978). Calculation if the solar radiation incident on inclined surfaces. In Proceedings first Canadian Solar Radiation Data Workshop. Toronto, Canada: Minister of Supply and Services Canada.

Ike, G. N., Usman, O., Alola, A. A., \& Sarkodie, S. A. (2020). Environmental quality effects of income, energy prices and trade: the role of renewable energy consumption in G-7 countries. The Science of the Total Environment, 137813, 137813. http://dx.doi.org/10.1016/j.scitotenv.2020.137813. PMid:32197283.

Instituto Nacional de Meteorologia - INMET. (2019). Brasília, DF. Recuperado em 30 de Janeiro de 2019, de http://www.inmet.gov.br/.

Kaushika, N. D., Mishra, A., \& Rai, A. K. (2018). Introduction to solar photovoltaic power. In N. D. Kaushika, A. Mishra, \& A. K. Rai. Solar photovoltaics (pp. 1-14). Cham: Springer. https://doi.org/10.1007/978-3-319-72404-1_1.

Kavlak, G., McNerney, J., \& Trancik, J. E. (2018). Evaluating the causes of cost reduction in photovoltaic modules. Energy Policy, 123, 700-710. http://dx.doi.org/10.1016/j.enpol.2018.08.015.

Kazmerski, L. L. (1997). Photovoltaics: a review of cell and module technologies. Renewable \& Sustainable Energy Reviews, 1(1-2), 71-170. http://dx.doi.org/10.1016/S1364-0321(97)00002-6.

Kojima, A., Teshima, K., Shirai, Y., \& Miyasaka, T. (2009). Organometal halide perovskites as visible-light sensitizers for photovoltaic cells. Journal of the American Chemical Society, 131(17), 6050-6051.

http://dx.doi.org/10.1021/ja809598r. PMid:19366264.

Kumar, N. M., Subathra, M. P., \& Moses, J. E. (2018). On-grid solar photovoltaic system: components, design considerations, and case study. In Proceedings of the 2018 4th International Conference on Electrical Energy Systems (ICEES) (pp. 616-619). USA: IEEE. http://dx.doi.org/10.1109/ICEES.2018.8442403

Lange, B. (1930). New photoelectric cell. Zeitschrift fur Physik, 31, 139.

Lee, G. R., Frearson, L., \& Rodden, P. (2011). An assessment of photovoltaic modelling software using real world performance data. In 26th European PV Solar Energy Conference (pp. 4339-4343). Hamburg, Germany: CCH. http://dx.doi.org/10.4229/26thEUPVSEC2011-5BV.2.47

Lima, L. C., Ferreira, L. A., \& Morais, F. H. B. L. (2017). Performance analysis of a grid connected photovoltaic system in northeastern Brazil. Energy for Sustainable Development, 37, 79-85.

http://dx.doi.org/10.1016/j.esd.2017.01.004.

Liu, B. Y. H., \& Jordan, R. C. (1963). The long-term average performance of flat-plate solar-energy collectors: with design data for the US, its outlying possessions and Canada. Solar Energy, 7(2), 53-74.

http://dx.doi.org/10.1016/0038-092X(63)90006-9. 
Liu, J., Chen, X., Yang, H., \& Li, Y. (2020). Energy storage and management system design optimization for a photovoltaic integrated low-energy building. Energy, 190, 116424.

http://dx.doi.org/10.1016/j.energy.2019.116424.

Miguel, A., Bilbao, J., Aguiar, R., Kambezidis, H., \& Negro, E. (2001). Diffuse solar irradiation model evaluation in the north Mediterranean belt area. Solar Energy, 70(2), 143-153. http://dx.doi.org/10.1016/S0038-092X(00)00135-3.

Mikhailova, M. P., Moiseev, K. D., \& Yakovlev, Y. P. (2019). Discovery of III-V Semiconductors: Physical Properties and Application. Semiconductors, 53(3), 273-290. http://dx.doi.org/10.1134/S1063782619030126.

Mondol, J. D., Yohanis, Y. G., \& Norton, B. (2007). Comparison of measured and predicted long term performance of grid a connected photovoltaic system. Energy Conversion and Management, 48(4), 1065-1080.

http://dx.doi.org/10.1016/j.enconman.2006.10.021.

NASA POWER. (2018). NASA Predction of Wordwild Energy Resources. Recuperado em 30 de Janeiro de 2019, de https://power.larc.nasa.gov/docs/methodology/data/\#solar.

Nejat, P., Jomehzadeh, F., Taheri, M. M., Gohari, M., \& Majid, M. Z. A. (2015). A global review of energy consumption, CO2 emissions and policy in the residential sector (with an overview of the top ten CO2 emitting countries). Renewable \& Sustainable Energy Reviews, 43, 843-862. http://dx.doi.org/10.1016/j.rser.2014.11.066.

Notton, G., Lazarov, V., \& Stoyanov, L. (2010). Optimal sizing of a grid-connected PV system for various PV module technologies and inclinations, inverter efficiency characteristics and locations. Renewable Energy, 35(2), 541-554. http://dx.doi.org/10.1016/j.renene.2009.07.013.

Organização das Nações Unidas - ONU. (2015). Transformando nosso mundo: a agenda 2030 para o Desenvolvimento Sustentável (Trad. Centro de Informação das Nações Unidas para o Brasil (UNIC Rio)). New York: ONU. Recuperado em 30 de setembro de 2019, de www.agenda2030.com.br

Orgill, J. F., \& Hollands, K. G. T. (1977). Correlation equation for hourly diffuse radiation on a horizontal surface. Solar Energy, 19(4), 357-359. http://dx.doi.org/10.1016/0038-092X(77)90006-8.

PYSOLAR. (2018). Pysolar Documentation. Recuperado em 01 de Fevereiro de 2020, de https://pysolar.readthedocs.io/en/latest/.

Reindl, D. T., Beckman, W. A., \& Duffie, J. A. (1990). Evaluation of hourly tilted surface radiation models. Solar Energy, 45(1), 9-17. http://dx.doi.org/10.1016/0038-092X(90)90061-G.

Reynolds, D. C., Leies, G., Antes, L. L., \& Marburger, R. E. (1954). Photovoltaic effect in cadmium sulfide. Physical Review, 96(2), 533. http://dx.doi.org/10.1103/PhysRev.96.533.

Richter, M., Kalisch, J., Schmidt, T., \& Elke, L. (2015). Best practice guide on uncertainty in PV modelling. (Vol. 2). Oldenburg: University of Oldenburg.

Roberts, J. J., Zevallos, A. A. M., \& Cassula, A. M. (2017). Assessment of photovoltaic performance models for system simulation. Renewable \& Sustainable Energy Reviews, 72, 1104-1123.

http://dx.doi.org/10.1016/j.rser.2016.10.022.

Saidi, K., \& Omri, A. (2020). The impact of renewable energy on carbon emissions and economic growth in 15 major renewable energy-consuming countries. Environmental Research, 109567, 109567.

http://dx.doi.org/10.1016/j.envres.2020.109567. PMid:32361260.

Schottky, W. (1930). Cuprous oxide photoelectric cells. Zeitschrift fur Physik, 31, 913.

Solergo. (2018). Projeto de sistemas fotovoltaicos conectados à rede de distribuição ou isolados. Recuperado em 20 de fevereiro de 2019, de https://electrographics.com.br/wp-content/uploads/2016/03/SOLergo-BRA-2015.pdf.

Thevenard, D., \& Pelland, S. (2013). Estimating the uncertainty in long-term photovoltaic yield predictions. Solar Energy, 91, 432-445. http://dx.doi.org/10.1016/j.solener.2011.05.006.

Tian, Y. Q., Davies-Colley, R. J., Gong, P., \& Thorrold, B. W. (2001). Estimating solar radiation on slopes of arbitrary aspect. Agricultural and Forest Meteorology, 109(1), 67-74. http://dx.doi.org/10.1016/S0168-1923(01)00245-3. 
Treble, F. C. (1980). Solar cells. IEE Proceedings A (Physical Science, Measurement and Instrumentation, Management and Education, Reviews), 127(8), 505-527. http://dx.doi.org/10.1049/ip-a-1.1980.0075.

Tsai, S. B., Yu, J., Ma, L., Luo, F., Zhou, J., Chen, Q., \& Xu, L. (2018). A study on solving the production process problems of the photovoltaic cell industry. Renewable \& Sustainable Energy Reviews, 82, 3546-3553. http://dx.doi.org/10.1016/j.rser.2017.10.105.

Uzar, U. (2020). Political economy of renewable energy: does institutional quality make a difference in renewable energy consumption? Renewable Energy, 155, 591-603. http://dx.doi.org/10.1016/j.renene.2020.03.172.

Villalva, M. G., Gazoli, J. R., \& Ruppert, E., Fo. (2009). Comprehensive approach to modeling and simulation of photovoltaic arrays. IEEE Transactions on Power Electronics, 24(5), 1198-1208.

http://dx.doi.org/10.1109/TPEL.2009.2013862.

Woodall, J. M., \& Hovel, H. J. (1972). High-efficiency Ga $1-{ }_{x} \mathrm{Al}_{x} \mathrm{As}-\mathrm{GaAs}$ solar cells. Applied Physics Letters, 21(8), 379-381. http://dx.doi.org/10.1063/1.1654421.

Editor: Fábio Duarte

Recebido: Nov. 22, 2019

Aprovado: Jul. 08, 2020 